\title{
EFFECTS OF POST WELD HEAT TREATMENT (PWHT) ON MECHANICAL PROPERTIES AND MICROSTRUCTURE OF EN AW-6082 T6 ALUMINUM ALLOY
}

\author{
Ciprian Pavel LUCIAN, Ion MITELEA, Ion Dragoş UŢU, Corneliu Marius CRĂCIUNESCU \\ Politehnica University of Timisoara, Timisoara, Romania, EU, \\ ciprian.lucian@student.upt.ro, ion.mitelea@upt.ro,dragos.utu@upt.ro, corneliu.craciunescu@upt.ro
}

https://doi.org/10.37904/metal.2019.741

\begin{abstract}
The issues which appears at fusion welding of 6082 T6 aluminum alloy are connected with hot cracking (solidification and liquation crackings), porosity and over aging of a portion from heat-affected zone (HAZ). Relatively high thermal expansion and the wide range solidification temperature of the Al alloy are the main causes of susceptibility to welding cracking. Moreover, over aging phenomenon of a portion from HAZ, due to the welding thermal cycle is manifested by the decrease in hardness and mechanical strength of the welded joint. The main objective followed by this paper is to restore the microstructure and the mechanical properties of the pulsed MIG welded joints made from $5 \mathrm{~mm}$ thickness sheets by applying a post weld heat treatment of solution quenching followed by artificial aging.
\end{abstract}

Keywords: Welding, heat treatment, microstructure

\section{INTRODUCTION}

Welded aluminum alloys are used in many industries (automotive, shipbuilding, aeronautics, transports, structural applications) due to the high ratio between mechanical strength and specific mass, a good corrosion resistance and due to attractive mechanical properties obtained through heat treatment $[1,2]$. The considerable interest in these alloys is due to the fact that two-thirds of all extruded products are made of these materials, and $90 \%$ of them belong to the 6xxx series [5]. In this series, 6082 T6 is one of the most widely used alloys. Optimizing the welding process requires a good understanding of the microstructures generated by the rapid temperature rise in the heat-affected area. The main problems by aluminum alloy welding EN AW 6082-T6 include the reduction of mechanical strength characteristics and hot cracking [3,4]. A series of metallurgical changes take place in the heat-affected zone (HAZ) during and immediately after welding. The expansion of the HAZ in the weld joint depends on the peak temperature and the shape of the thermal cycle during fusion welding, which will result in a pronounced increase of the crystalline grains in the weld seam and near the fusion line. The schematic representation of the microstructure modification during the welding of the aluminum alloys at room temperature is shown in Figure 1. Accordingly, the heat-affected zone comprises a partially molten strip, a strip which has reached specific temperatures of solution heat treatment and a strip which is characteristic of the over aging phenomenon. There is also a potential for loss of alloying elements from the molten metal bath, which can lead to a reduction in mechanical strength. Magnesium has a low boiling point and can be lost or oxidized during welding. Magnesium loss is the most significant when MIG welding process is used, but a particular attention to the selection of the shielding gas will minimize this problem.

Much of the weldability problems are referred to the large difference between the critical points solidus and liquidus which can lead to liquation crackings in heat-affected zone. Some improvements in weldability have been achieved through careful control of welding metallurgy. During welding, liquid films are formed on the grain boundaries in the area adjacent to the fusion line. These liquid films lead to the formation of microscopic intergranular cracks after welding, which can create conditions for later fragile intergranular breakage with brittle character. 


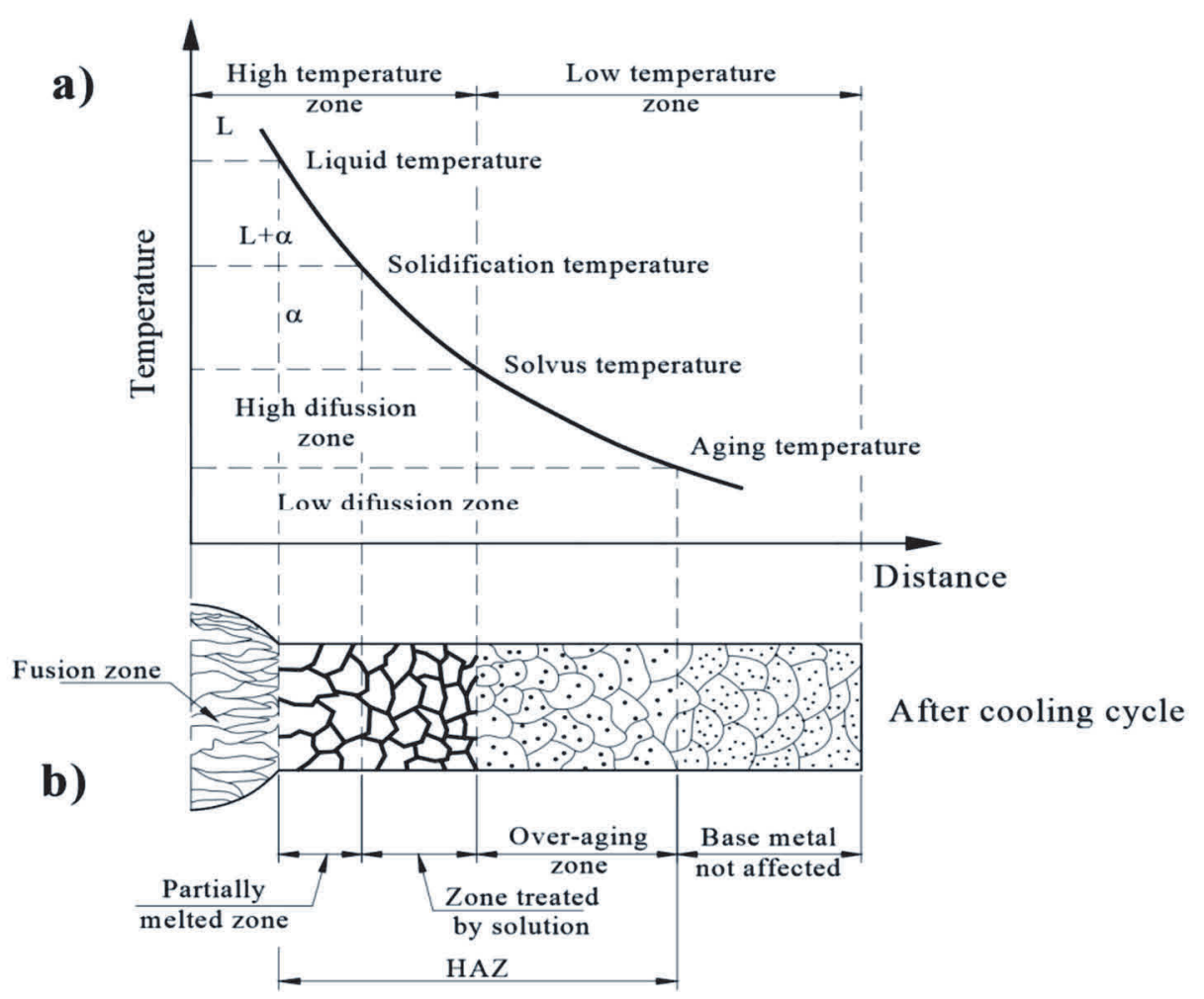

Figure 1 Schematic of structural changes during welding of thermally treatable aluminum alloys: a) Thermal cycle b) Microstructure of the characteristic areas [3]

Changing the microstructure of precipitates is the key factor that influences the mechanical strength of thermally treatable aluminum alloys. Pre-existing precipitation status can be changed by the following distinct ways:

- $\quad$ dissolution of precipitates;

- $\quad$ the growth or coagulation of pre-existing precipitates;

- $\quad$ transformation of metastable phases into more stable forms;

- nucleation of new particles.

This paper aims to restore the degraded microstructure of the HAZ and to improve the mechanical properties of the welded joint by applying a post weld heat treatment of solution quenching followed by artificial aging.

\section{THE EXPERIMENTAL PROCEDURE}

From butt welded sheets obtained through pulsed MIG process [4], samples were taken with transverse faces (perpendicular to the longitudinal welding axis) which served to perform mechanical tests and metallographic examinations. The cyclic chart of the heat treatment applied to these samples is shown in Figure 2. Subsequently, samples were taken for static tensile tests, hardness tests, X-ray diffraction analysis, and scanning electron microscopy examinations.

\section{INTERPRETATION OF EXPERIMENTAL RESULTS}

Table 1 shows the average values of tensile strength and elongation at break at room temperature for the welded state without further heat treatment, and the state obtained after welding and post-treatment treatment for solution + artificial aging. 


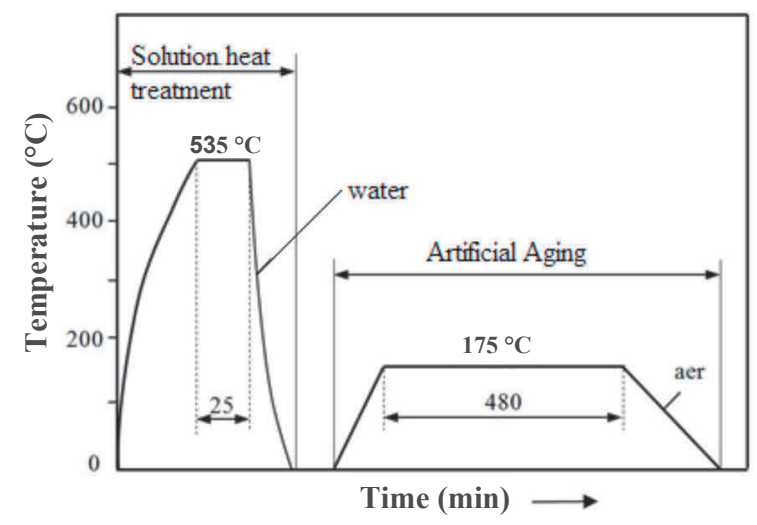

Figure 2 Post weld heat treatment

From the analysis of these data, it can be noticed that the microstructure of the welded joint was restored, the breaking location was transferred from HAZ [4] to the welded seam. However an increase in tensile strength of the welded joint occurred up to $248-254 \mathrm{~N} / \mathrm{mm}^{2}$. Differences in chemical composition between the base metal and the filler material (AISi5), even if they have been mixed each other (the dilution phenomenon), justify the breaking of the welded joint in the welded seam.

Table 1 Values of some mechanical characteristics

\begin{tabular}{|c|c|c|c|c|}
\hline Sample No. & Source & $\boldsymbol{R}_{\boldsymbol{m}}\left(\mathrm{N} / \mathrm{mm}^{2}\right)$ & $\boldsymbol{A}_{\mathbf{5}}(\%)$ & Place of fracture \\
\hline 1 & Base Metal, BM & 328 & 19 & - \\
\hline 2 & BM & 330 & 15.5 & - \\
\hline 3 & BM & 330 & 16.0 & Weld seam \\
\hline 4 & Welded Joint, WJ & 248 & 15.5 & Weld seam \\
\hline 5 & WJ & 252 & 13.8 & Weld seam \\
\hline 6 & WJ & 251 & 14.6 & Weld seam \\
\hline 7 & WJ & 251 & 15 & Weld seam \\
\hline 8 & WJ & 254 & 14.8 & \\
\hline
\end{tabular}

The hardness gradient curve on the welded joint cross section after the applied heat treatment (Figure 3) shows that by restoring the HAZ microstructure, in this area of the welded joint, hardness values similar to the base metal were obtained, and there was also a significant increase in the hardness of the weld seam.

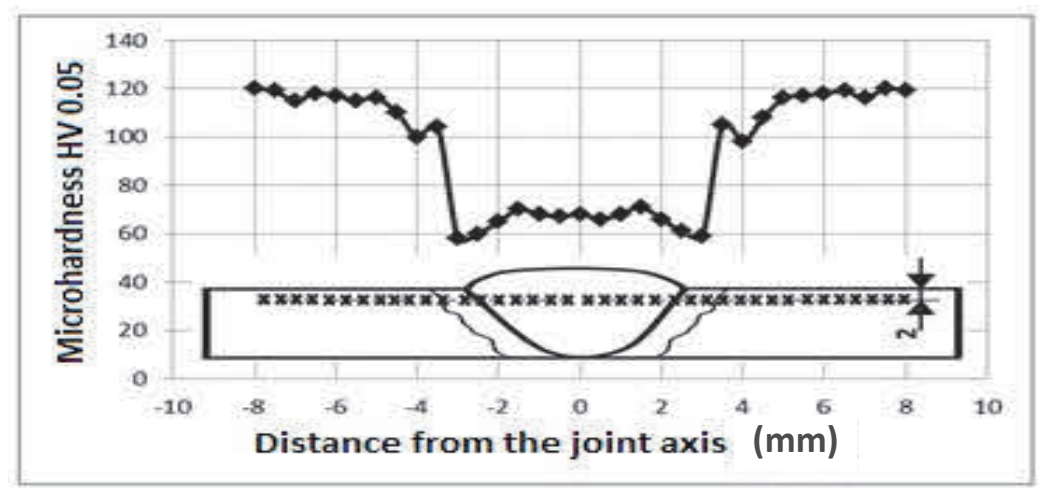

Figure 3 Variation of hardness with the distance from welded joint axis 
X-ray diffraction analyses performed on base metal and weld seam after the post heat treatment (Figure 4) confirmed that $\mathrm{Mg}$ and $\mathrm{Si}$ are the main alloying elements that increase the mechanical strength of the alloy, as a result of both hardening by precipitation and hardening by solid solutions.

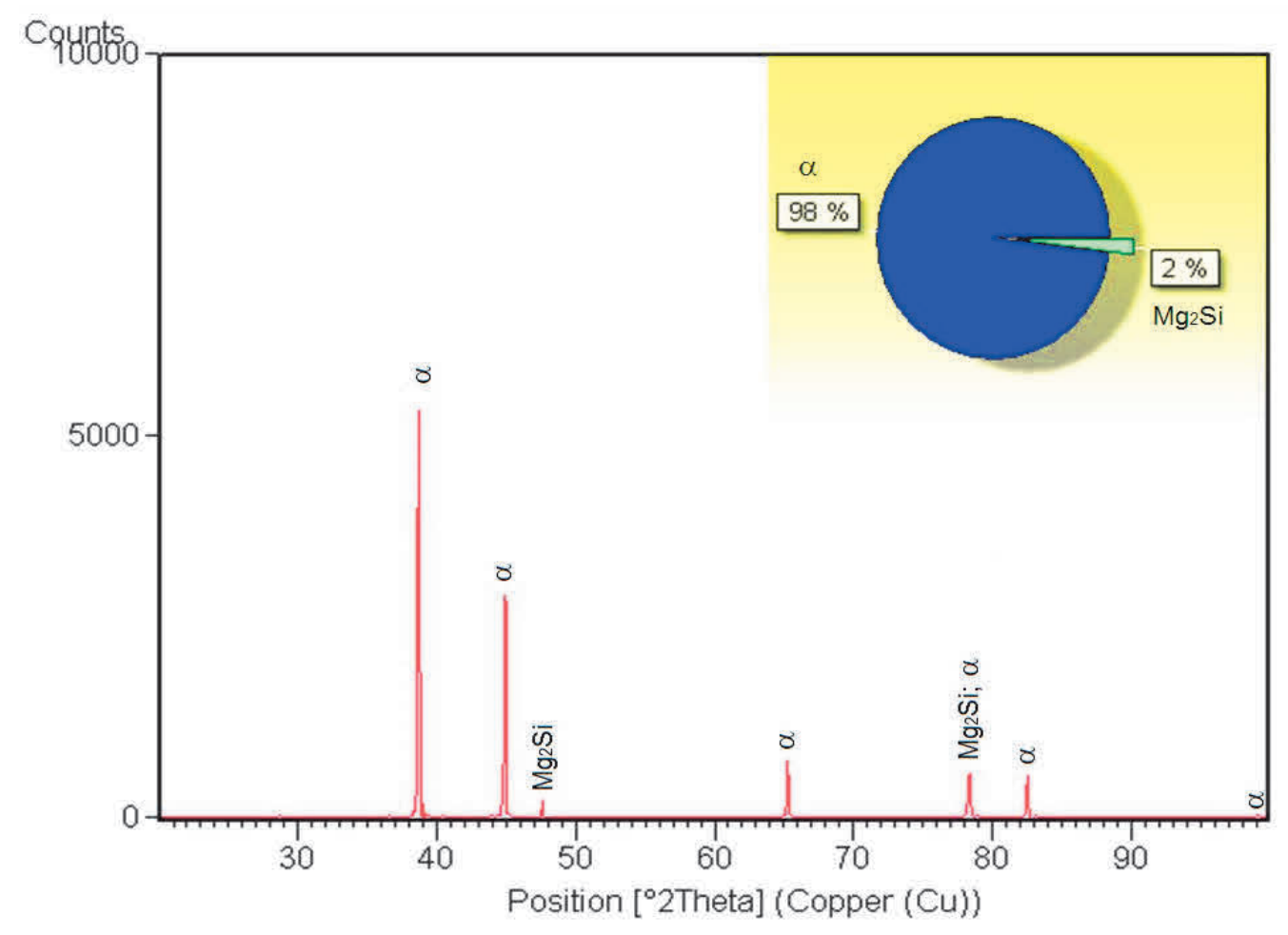

a)

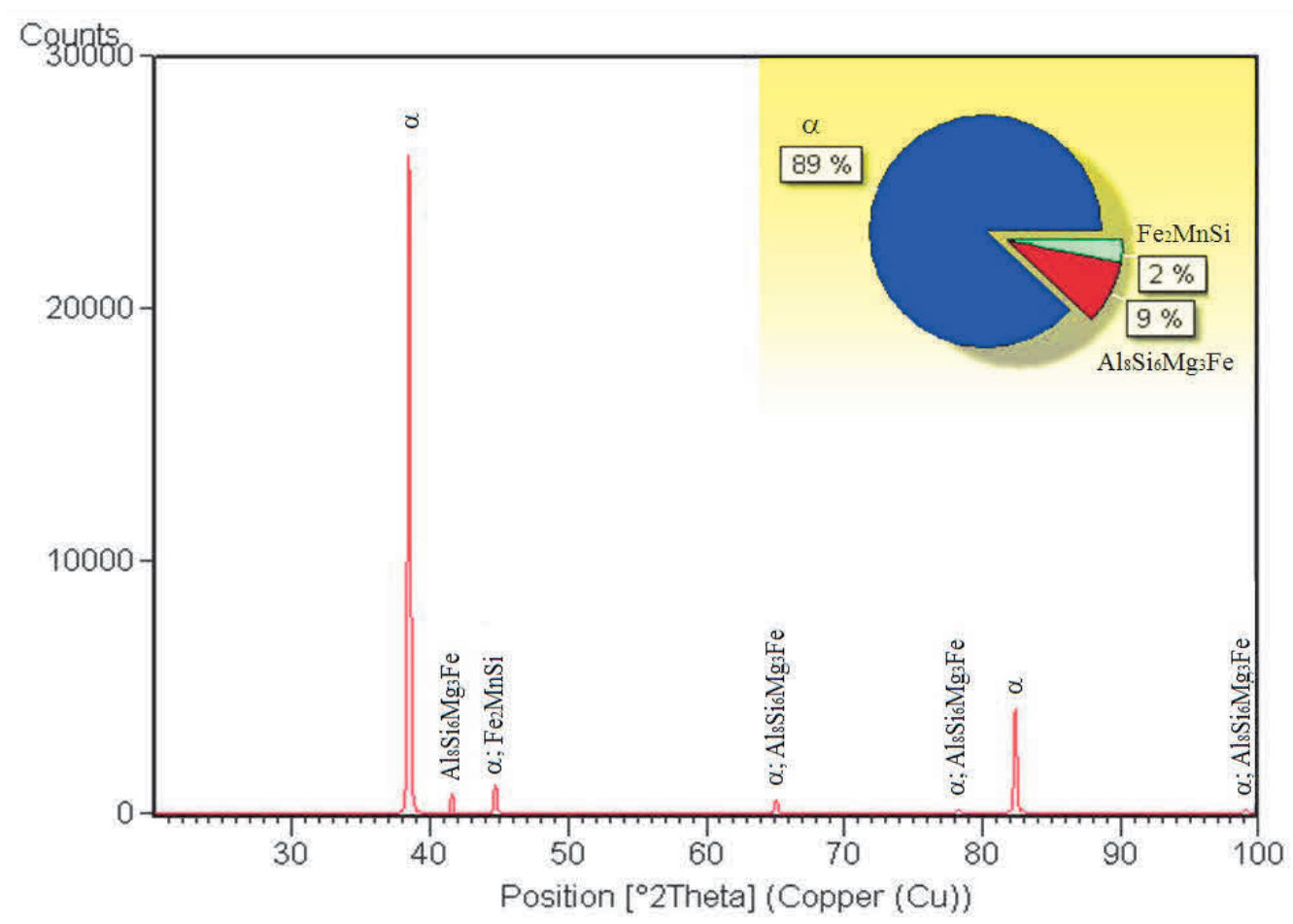

b)

Figure 4 XRD patterns: a) welded seam; b) base metal 
Scanning electron microscopy (SEM) investigations shown that the microstructure of the weld seam and base metal consists of the solid solution alpha with Al-base, in which the precipitated phases with hardening role are dispersed (Figure 5).

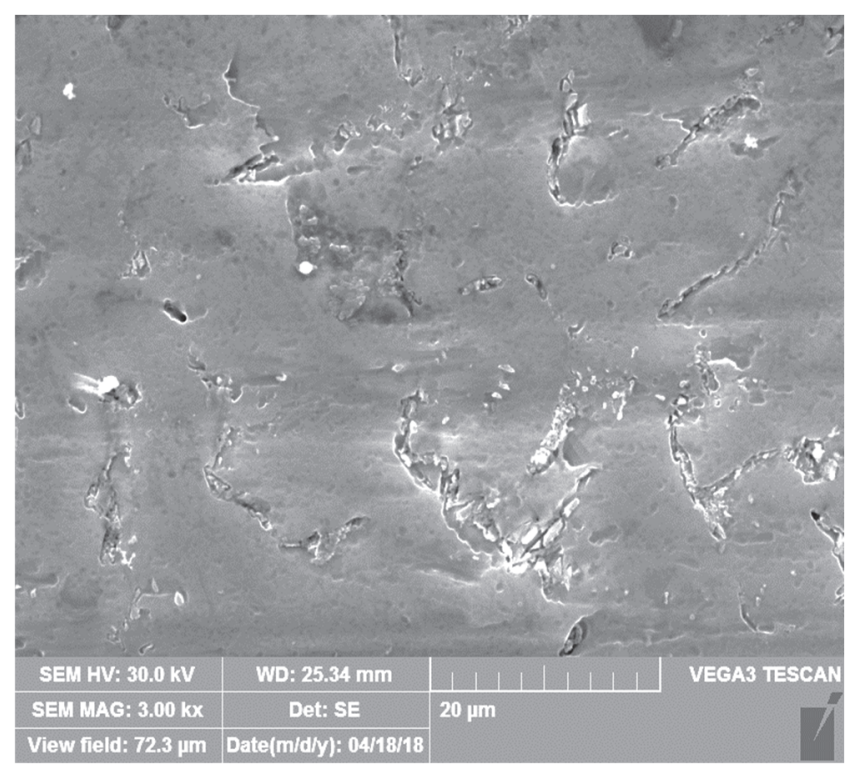

a)

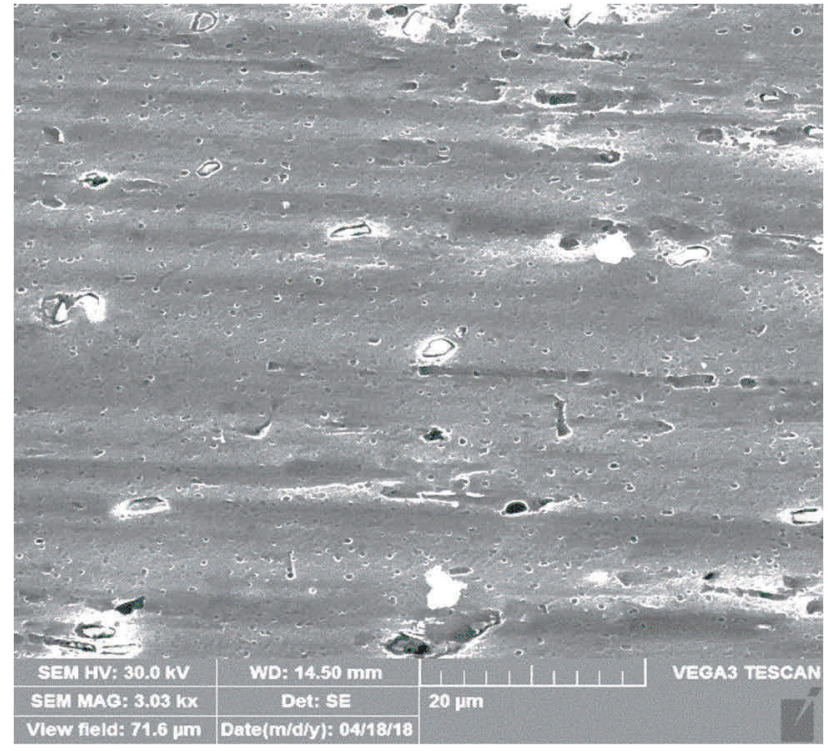

b)

Figure 5 SEM images: a) welded seam; b) base material

EDX analyse confirmed that due to the dilution phenomenon, some differences in chemical composition occur between the weld seam and base metal (Figure 6). They justify the nature and the different proportion of secondary phase precipitations in the two areas of the welded joint, affecting the level of the obtained mechanical characteristics.

a)

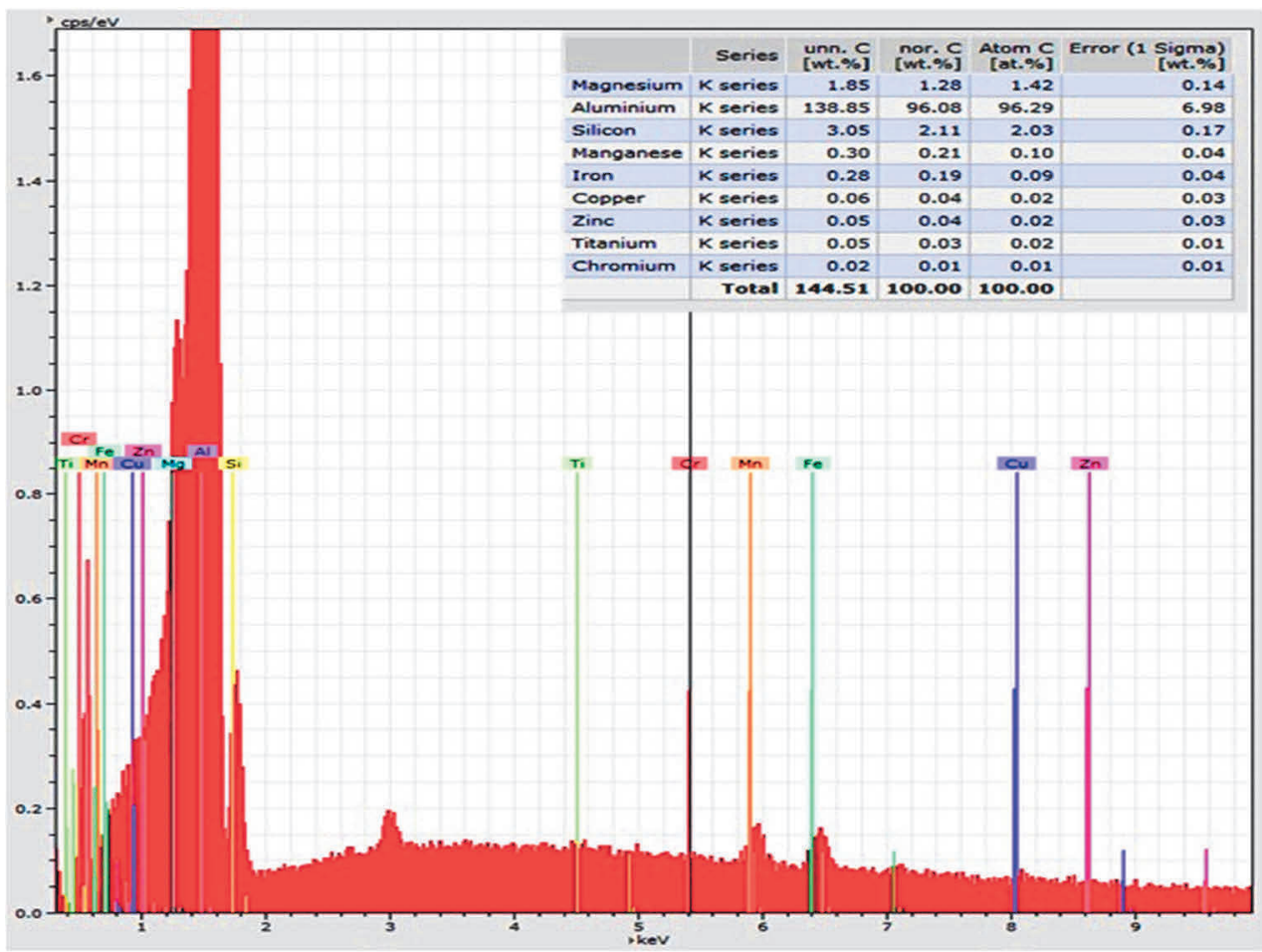

Figure 6a) EDX analysis results: welded seam 
b)

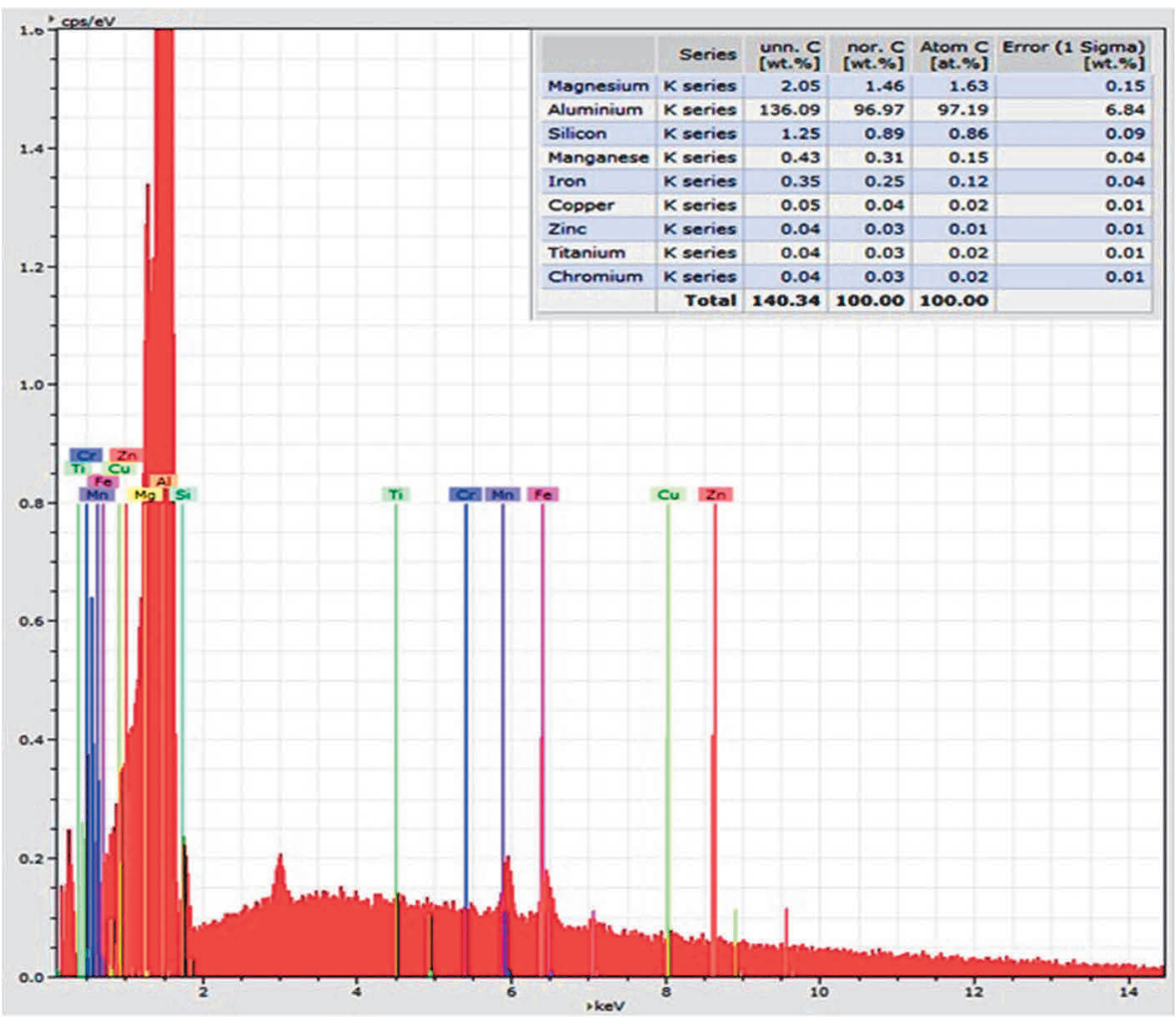

Figure 6b) EDX analysis results: base material

\section{CONCLUSION}

The mechanical properties of welded MIG aluminum alloy joints, EN AW 6082, can be restored by post weld heat treatment of solution quenching followed by artificial aging.

The level of mechanical characteristics obtained is determined by the nature, density and magnitude of the precipitated secondary phases from the supersaturated solid solution.

\section{REFERENCES}

[1] AKHTER, L. and BURGER, H.P. Effect of pre/post T6 heat treatment on the mechanical properties of laser welded SSM cast A356 aluminum alloy. J. Mat. Sci. Eng. A. 2007. vol. 447, pp. 192-166.

[2] HUANG, C. and KOU, S. Liquation cracking in full-penetration Al-Mg-Si welds. Weld J. 2004, pp. 111-122.

[3] AMBRIZ, R.R. and JARAMILLO, D. Mechanical behavior of precipitation hardened aluminum alloys welds. Light Metal Alloys Applications. Intechopen. 2014, Available from: DOI 10.5772/57069.

[4] LUCIAN, CP., MITELEA, I., BURCĂ, M. and UTTU, I.D. Mechanical behaviour of MIG pulsed welded joints from 6082 T6 aluminum alloy. In IOP Conf. Series: Materials Science and Engineering. 2018. vol. 416, Available from: DOI: 10.1088/1757-899X/416/1/012009

[5] BUHA, J., LUMLEY, R.N. and CROSKY, A.G. Microstructural development and mechanical properties of interrupted aged Al-Mg-Si-Cu alloy. J. Metall Mater. Trans. A. 2006. vol. 37A, pp. 3119-3130. 